\section{Circulating markers of arterial thrombosis and late-stage age-related macular degeneration: a case-control study}

AR Rudnicka', PK MacCallum², R Whitelocke ${ }^{3}$ and TW Meade ${ }^{4}$

\author{
Abstract \\ Purpose The aim of this study was to \\ examine the relation of late-stage age-related \\ macular degeneration (AMD) with markers of \\ systemic atherothrombosis.
}

Methods A hospital-based case-control study of AMD was undertaken in London, UK.

Cases of AMD $(n=81)$ and controls $(n=77)$

were group matched for age and sex. Standard protocols were used for colour fundus photography and to classify AMD; physical examination included height, weight, history of or treatment for vascular-related diseases and smoking status. Blood samples were taken for measurement of fibrinogen, factor VIIc (FVIIc), factor VIIIc, prothrombin fragment F1.2 (F1.2), tissue plasminogen activator, and von Willebrand factor. Odds ratios from logistic regression analyses of each atherothrombotic marker with AMD were adjusted for age, sex, and established cardiovascular disease risk factors, including smoking, blood pressure, body mass index, and total cholesterol.

Results After adjustment FVIIc and possibly F1.2 were inversely associated with the risk of AMD; per 1 standard deviation increase in these markers the odds ratio were, respectively, 0.62 (95\% confidence interval 0.40 , $0.95)$ and $0.71(0.46,1.09)$. None of the other atherothrombotic risk factors appeared to be related to AMD status. There was weak evidence that aspirin is associated with a lower risk of AMD.

Conclusions This study does not provide strong evidence of associations between AMD and systematic markers of arterial thrombosis, but the potential effects of FVIIc, and F1.2 are worthy of further investigation.
Eye (2010) 24, 1199-1206; doi:10.1038/eye.2010.8; published online 12 February 2010

Keywords: age-related macular degeneration; atherothrombosis; factor VII; aspirin

\section{Introduction}

The most common cause for adult blind registration in many developed countries is The prevalence of AMD rises sharply over the age of 65 years, ${ }^{4,5}$ and it has been estimated that $4 \%$ over 75 years ${ }^{4}$ and up to $12 \%{ }^{5}$ of people over 80 years of age are visually impaired due to AMD. The natural history of the different types of AMD is not clearly defined and whether the two subtypes of AMD (geographic atrophy and neovascular AMD) are the same disease is controversial because both can be found in the same patient. ${ }^{6}$ The most consistently identified risk factor for AMD is smoking. ${ }^{7-10}$ Studies have reported associations between AMD and established cardiovascular risk factors, ${ }^{10-19}$ markers of atherosclerotic disease $\mathrm{e}^{20,21}$ and diagnosed cardiovascular disease, ${ }^{10,22,23}$ but not universally. ${ }^{19,24,25}$ Several markers of systemic inflammation and haemostasis have been investigated in relation to AMD, including plasma fibrinogen, ${ }^{14,26-29}$ plasminogen activator inhibitor, ${ }^{29}$ C-reactive protein, ${ }^{28-32}$ von Willebrand factor (VWF), ${ }^{26,29}$ and white blood cell count, ${ }^{19,24,26,29,33}$ but with inconclusive findings. Some of these factors of inflammation are related to markers of arterial thrombosis, and it is now possible to define a hypercoagulable state by measuring levels of certain coagulation factors and molecular age-related macular degeneration (AMD) ${ }^{1-3}$
${ }^{1}$ Division of Community Health Sciences, St George's, University of London, Cranmer Terrace, London, UK

${ }^{2}$ Wolfson Institute of Preventive Medicine, Queen Mary's School of Medicine and Dentistry, Charterhouse Square, London, UK

${ }^{3}$ Ophthalmology Department, Barts and The London NHS Trust, St Bartholomew's Hospital, London, UK

${ }^{4}$ London School of Hygiene and Tropical Medicine, London, UK

Correspondence: AR Rudnicka, Division of Community Health Sciences, St George's, University of London, Cranmer Terrace, London SW17 ORE, UK Tel: + 440208725 2799; Fax: + 4402087253584 . E-mail: arudnicka@ sgul.ac.uk

Received: 6 August 2009 Accepted in revised form: 11 January 2010 Published online: 12 February 2010 
markers in the blood. Large epidemiological studies have shown that fibrinogen and markers of coagulation activity, including factor VII coagulant activity (FVIIc) and factor VIII coagulant activity (FVIIIC), are independent risk factors for the development of coronary heart disease, ${ }^{34-37}$ and meta-analyses of prospective cohort studies have established that levels of fibrinogen, ${ }^{38} \mathrm{VWF}^{39}$ and tissue-type plasminogen activator (t-PA) antigen ${ }^{40}$ are positively related to incident coronary heart disease. Therefore, there is strong evidence linking this laboratory-based definition of a prothrombotic state with clinical thrombosis. Whether AMD is also related to these markers of systemic atherothrombotic activity requires clarification. The aim of this study was to examine the relation of late-stage AMD with systemic markers of atherothrombosis; fibrinogen, FVIIc, FVIIIc, prothrombin fragment F1.2 (F1.2; a molecular marker of thrombin generation in vivo), t-PA activity (a marker of upregulation of fibrinolysis), and VWF (a glycoprotein secreted by vascular endothelial cells that enhances haemostasis and thrombosis).

\section{Materials and methods}

\section{Study design}

The medical records of patients with appointments at the Ophthalmology Department, Bart's and The London NHS Trust between February 1996 and August 2002 were examined by the clinic co-ordinator for potentially eligible cases and controls. The senior ophthalmologist certified the eligibility of patients for inclusion in the study. Patients were invited to participate in the study when they attended for their eye clinic appointment. Individuals with systematic inflammatory disease were excluded. Eligible cases and controls were given an information sheet outlining the purpose of the study and what it would involve. Informed written consent was sought from all potential eligible participants before undertaking venepuncture and additional demographic data collection. Cases and controls were all resident in the local clinic area in East London, UK, aged over 45 years and group matched for age and sex. The study received ethics committee approval from the East London and City Health Authority and was conducted within the tenets of the Declaration of Helsinki Principles.

\section{Ocular examination and AMD grading}

Both eyes of cases and controls underwent measurement of refractive error, best-corrected visual acuity, intra-ocular pressure, fundus photography (Kowa RCXV camera,
30 degree field, KOWA, Japan). Retinal photographs were read independently and in a blind manner according to the International ARM Epidemiological Study Group criteria. ${ }^{41}$

Diagnostic criteria for AMD were based on late-stage age-related maculopathy, that is atrophic or neovascular macular degeneration together with a visual acuity worse than $6 / 6$ or distortion on the Amsler grid. In brief, the characterising features included drusen (any type) in either eye and

(1) geographic atrophy: well-demarcated atrophic area of retinal pigment epithelium (RPE) (a sharply defined area of hypopigmentation or depigmentation) with apparent absence of RPE and increased visibility of underlying choroidal vessels or

(2) neovascular AMD: RPE detachment or serous detachment of the sensory retina, and/or subretinal or sub-RPE haemorrhage and/or subretinal fibrous scars

Patients with diseases other than AMD associated with choroidal neovascularisation, such as presumed ocular histoplasmosis syndrome, angoid streaks, choroidal rupture, diabetic retinopathy, chorioretinitis, high myopia, congenital diseases, or trauma, were excluded from study. Controls were attending for a range of other ocular conditions, including vitreous floaters, posterior vitreous detachment, nasolacrimal duct obstruction, lid disorders, primary open angle glaucoma, cataract, conjunctivitis and did not show any signs of neovascularassociated or geographic atrophy-associated AMD.

\section{Laboratory methods}

Venepuncture was performed between 0830 and 1200 hours with the subjects sitting and $25 \mathrm{ml}$ of non-fasting venous blood samples were taken into Vacutainer tubes containing no anticoagulant (for serum) or $0.105 \mathrm{M}$ citrate (9:1 vol/vol) and kept on ice or at room temperature as appropriate until centrifugation. Samples for t-PA activity were collected into acidified citrate $(\mathrm{pH} 4)$ and kept on ice until centrifugation. Samples were centrifuged at room temperature for $10 \mathrm{~min}$ at $1500 \mathrm{~g}$ and the resulting plasma and serum were stored in aliquots at $-80^{\circ} \mathrm{C}$. Fibrinogen was determined by the Clauss method $^{42}$ (MDA 180 coagulometer; Biomerieux, Basingstoke, UK). Plasma factor VIIc activity (FVIIc) was assayed by the Northwick Park method. ${ }^{43}$ Factor VIIIc activity (FVIIIc) was measured in a one-stage assay using FVIII-deficient plasma (DiaGen, East Rutherford, UK). Plasma F1.2 was measured by ELISA (Behringwerke AG, Marburg, Germany). The activity of t-PA was assayed using Coatest PAI-1 kits (S2403; Chromogenix, Molndal, Sweden). Laurell electroimmunoassay using antibodies 
supplied by Dako Ltd, Ely, UK, was used to measure VWF antigen. All biochemical analyses were performed at the MRC Epidemiology and Medical Care Unit, Wolfson Institute of Preventive Medicine and monitored for internal quality control using Levey-Jennings plots.

A second blood sample was taken on average 6 weeks later. The average of the two readings for each analyte was used in the analyses throughout. As samples were stored both samples from each patient were measured at the same time to minimise inter-assay variability.

\section{Demographic data collection}

The clinic nurse took measures of blood pressure, height, and weight at one visit and completed standardised interviewer-administered questionnaire, including history of cardiovascular events, cardiovascular risk factors and medication use (doctor prescribed and over the counter), ethnic origin, current occupational status, smoking history, alcohol consumption, presence of major chronic disease. Use of antiplatelet therapy was defined as any dose of aspirin, dipyridamole, or clopidogrel. Doctor-prescribed medications taken by patients were identified and coded using standard procedures (British National Formulae). From the medical records data on the presence of concurrent, we extracted ophthalmic disorders.

\section{Statistical analysis and sample size}

The sample size calculation was based on logistic regression analysis designed to detect a difference between cases and controls of 0.5 standard deviations in continuous outcome measures of fibrinogen and factor VII with a power of $90 \%$ and $5 \%$ statistical significance ( $n=85$ in each group). This expected amplitude of change was based on reported associations between agerelated maculopathy and haemostatic markers. ${ }^{29}$ This sample size was also considered consistent with numbers of patients expected in practice over a 3-year period.

Demographic characteristics were examined in cases and controls to ensure that the groups were broadly similar with respect to age and sex. $\chi^{2}$-Tests were performed to examine univariate associations between risk of AMD and sex, diagnosis of cataract, diagnosis of glaucoma, medical history or treatment for cardiovascular disease, hypertension (defined as blood pressure of 160/95 or use of any antihypertensive medication), smoking status (never, ex-smoker, current smoker), and consumption of alcohol (drinker vs nondrinker). Taking the average of two independent measures of each biochemical marker minimised the influence of regression dilution bias, which is the phenomenon of associations being biased towards the null when only single measurements of a risk factor are made. ${ }^{44}$ Fibrinogen, t-PA activity, and VWF were log transformed to normalise their distributions. Mean levels of the thrombotic risk factors with $95 \%$ confidence intervals (CI) were determined for cases and controls with adjustment for age, sex, and smoking status. Logistic regression analysis adjusting for age, sex, smoking status, and then additionally for established cardiovascular risk factors (body mass index, total cholesterol, and systolic blood pressure) was used to examine the association between the risk of AMD and levels of fibrinogen, FVIIc, FVIIIc, F1.2, t-PA, and VWF. Odds ratios and $95 \%$ CIs are presented per 1 standard deviation (SD) increase in each risk factor.

\section{Results}

Table 1 shows that cases were on average 4 years older than controls (median age 78 vs 74 years) and $37 \%$ of

Table 1 Characteristics of study population

\begin{tabular}{|c|c|c|}
\hline & $\begin{array}{c}\text { Cases of } A M D \\
\mathrm{~N}=81 \\
\text { Mean }(S D)\end{array}$ & $\begin{array}{c}\text { Controls } \\
\mathrm{N}=77 \\
\text { Mean }(S D)\end{array}$ \\
\hline Age (years) & $77.1(8.9)$ & $73.6(7.2)^{\mathrm{a}}$ \\
\hline \multicolumn{3}{|l|}{ Blood pressure } \\
\hline Systolic (mm Hg) & $147.1(23.4)$ & $140.6(23.2)$ \\
\hline Diastolic (mm Hg) & $78.7(11.2)$ & $78.8(10.7)$ \\
\hline \multicolumn{3}{|l|}{ Serum total } \\
\hline Cholesterol (mmol/l) & $5.8(1.5)$ & $6.1(1.4)$ \\
\hline \multirow[t]{2}{*}{ Body mass index $\left(\mathrm{kg} / \mathrm{m}^{2}\right)$} & $26.0(4.1)$ & $25.6(3.9)$ \\
\hline & \multicolumn{2}{|c|}{ Percentages } \\
\hline Male & 37 & $53^{\mathrm{a}}$ \\
\hline Cataract & 36 & 29 \\
\hline Glaucoma & 7.4 & 10.4 \\
\hline \multicolumn{3}{|l|}{ Medical history ${ }^{\mathrm{b}}$} \\
\hline Myocardial infarction & 12.4 & 13.0 \\
\hline Cerebrovascular event & 7.4 & 10.4 \\
\hline Hypertension & 53 & 51 \\
\hline Angina & 12.4 & 19.5 \\
\hline \multicolumn{3}{|l|}{ Medications } \\
\hline ACE inhibitors & 13.6 & 19.4 \\
\hline Nitrates + & 22 & 26 \\
\hline Aspirin & 23 & 35 \\
\hline Antiplatelets & 21 & 32 \\
\hline Alcohol drinker & 37 & 34 \\
\hline Ex-smokers & 47 & 45 \\
\hline Current smokers & 16 & 17 \\
\hline
\end{tabular}

Nitrates + includes other vasodilators and calcium channel blockers ${ }^{a} P$-values statistically significant at $5 \%$ level: from a $\chi^{2}$-test for categorical variables and $t$-test for continuous variables.

befined as self-reported doctor diagnosis or treatment for this condition. 
cases and $53 \%$ of controls were men. The final casecontrol status was confirmed by the consultant ophthalmologist examining the medical notes and photographs. A few cases were excluded because they could not be classified as a definite case or definitive control resulting in more men in the control group. Of patients approached, $79 \%$ of cases and $67 \%$ of controls agreed to participate in the study. The majority of participants were white $(92 \%)$ and this negates any potential to examine ethnic differences. Crude analyses did not reveal any difference between cases and controls in the prevalence of glaucoma, cataract, history of cardiovascular diseases, smoking, alcohol consumption, or self-reported usage of the medications listed in Table 1 except for possibly aspirin (23\% of cases vs $35 \%$ of controls) and anti-platelet therapy ( $21 \%$ of cases $v s 32 \%$ of controls).

Table 2 shows that on average levels of fibrinogen and VWF were marginally higher in cases than in controls

Table 2 Adjusted mean levels of atherothrombotic risk factors (95\% CIs) in cases of AMD and controls

\begin{tabular}{|c|c|c|}
\hline \multirow[t]{2}{*}{ Risk factor } & \multicolumn{2}{|c|}{ Adjusted means ${ }^{\mathrm{a}}(95 \% \mathrm{CI})$} \\
\hline & Cases & Controls \\
\hline $\begin{array}{l}\text { Fibrinogen } \\
(\mathrm{mg} \text { per } 100 \mathrm{ml})^{\mathrm{b}}\end{array}$ & $358.3(345.1,372.1)$ & $357.8(344.3,371.9)$ \\
\hline Factor VIIc (\% standard) & $131(122,139)$ & $145(137,154)$ \\
\hline Factor VIIIIc (\% standard) $)^{\mathrm{b}}$ & $145(135,157)$ & $153(142,165)$ \\
\hline $\begin{array}{l}\text { Prothrombin fragment } \\
\text { F1.2 (nM) })^{\mathrm{b}}\end{array}$ & $1.88(1.66,2.13)$ & $2.29(2.02,2.60)$ \\
\hline $\begin{array}{l}\text { Tissue plasminogen } \\
\text { activator }(\mathrm{IU} / \mathrm{ml})^{\mathrm{b}}\end{array}$ & $2.23(1.91,2.61)$ & $2.23(1.90,2.61)$ \\
\hline $\begin{array}{l}\text { Plasminogen activator } \\
\text { inhibitor type } 1(\mathrm{IU} / \mathrm{ml})^{\mathrm{b}}\end{array}$ & $9.67(8.36,11.18)$ & $10.50(7.18,15.35)$ \\
\hline $\begin{array}{l}\text { von Willebrand factor } \\
\text { (\% standard) }\end{array}$ & $118(111,126)$ & $115(107,123)$ \\
\hline
\end{tabular}

after controlling for age, sex, and smoking status. Levels of all the other risk factors (except t-PA) were marginally lower in cases compared with controls.

Table 3 shows odds ratios adjusted for age, sex, and smoking status and additionally for body mass index, systolic blood pressure, and total serum cholesterol. In the fully adjusted model, a standardised increase in FVIIc reduced the risk of AMD by $38 \%$ (95\% CI 5-60\% decrease). There is some evidence of an inverse association with F1.2 in the basic adjustment model (29\% reduction in risk; $95 \% \mathrm{CI}$ from $52 \%$ reduction to $4 \%$ increase) but this association is attenuated in the fully adjusted model. None of the other atherogenic/ haemostatic makers appeared to be related to the prevalence of AMD.

With adjustment for age, sex, and smoking status, aspirin reduced the risk of AMD by $53 \%(\mathrm{OR}=0.47 ; 95 \%$ CI $0.20-1.08, P=0.07)$ but after full adjustment the odds ratio was attenuated towards the null $(\mathrm{OR}=0.61 ; 95 \% \mathrm{CI}$ $0.23-1.57, P=0.21)$. Use of anti-platelet therapy more generally yielded, not surprisingly, very similar results (data not presented).

\section{Conclusion}

To the authors' knowledge, this is the first study that examines the association of t-PA activity, F1.2, FVIIc, and FVIIIc with AMD. Cases of AMD had lower levels of FVIIc, marginally lower levels of F1.2, and were less likely to be using aspirin (or antiplatelet therapy) when compared to controls without AMD. These associations were attenuated after adjustment for age, sex, and smoking status but remained statistically significant for FVIIc and borderline for F1.2 and aspirin use (or antiplatelet therapy). With additional adjustment for established cardiovascular risk factors, the association with FVIIc remained stable but for F1.2 and aspirin the evidence for an association was weakened further.

The potential mechanism for the inverse association of FVIIc with AMD is not clear. The main established function of FVII is initiation of the process of coagulation

Table 3 Adjusted odds ratios for AMD per 1 SD increase in each atherothrombotic risk factor with corresponding 95\% CI and $P$-values

\begin{tabular}{lcccc}
\hline Risk factor & Adjusted odds ratios ${ }^{\mathrm{a}}$ (95\% CI) & P-value & Adjusted odds ratios ${ }^{\mathrm{b}}(95 \%$ CI) & P-value \\
\hline Fibrinogen $^{\mathrm{c}}$ & $0.98(0.70,1.38)$ & 0.92 & $0.87(0.58,1.31)$ & 0.49 \\
Factor VIIc $^{c}$ & $0.62(0.41,0.92)$ & 0.02 & $0.62(0.40,0.95)$ & 0.03 \\
Factor VIIIc $^{\mathrm{C}}$ & $0.81(0.56,1.16)$ & 0.24 & $0.88(0.60,1.30)$ & 0.52 \\
Prothrombin fragment F1.2 $^{\mathrm{c}}$ & $0.71(0.48,1.04)$ & 0.08 & $0.71(0.46,1.09)$ & 0.11 \\
Tissue plasminogen activator $^{\mathrm{c}}$ & $0.96(0.67,1.37)$ & 0.81 & $0.85(0.56,1.28)$ & 0.43 \\
von Willebrand factor & $1.13(0.80,1.60)$ & 0.47 & $1.23(0.84,1.79)$ & 0.29 \\
\hline
\end{tabular}

adds ratios are per 1 standard deviation increase in risk factor with 95\% CIs in parenthesis adjusted for age in years, sex, and smoking status.

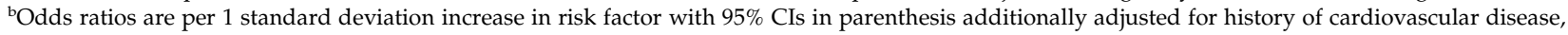
body mass index, systolic blood pressure, and total cholesterol as continuous variables.

${ }^{c}$ Variables that were $\log$ transformed for logistic regression analyses. 
on binding to tissue factor; thereby, leading to thrombin generation. F1.2 is a molecular marker of thrombin generation in vivo and is positively correlated with $\mathrm{FVII}^{45}$ (correlation coefficient $0.44, P<0.0001$ in this study). It is possible that patients with AMD may express increased tissue factor as a consequence of more extensive vascular disease and this could bind FVII, resulting in lower circulating FVIIc levels. However, if that were the case, levels of F1.2 might be higher reflecting increased thrombin generation in vivo whereas the reverse was seen. Alternatively, FVII synthesis might be depressed in AMD, or FVIIc might be inactivated by increases in leukocyte elastase $^{46}$ resulting from an inflammatory process in patients with AMD. However, the evidence for an inflammatory process in AMD is inconclusive. ${ }^{26-29,33,47}$ The US Physicians study ${ }^{48}$ suggested a potential beneficial effect of low-dose aspirin that agrees with our findings adjusting for age, sex, and smoking status. However, in the fully adjusted model, there does not appear to be any association with aspirin as found by others. ${ }^{49}$

Our findings agree with other larger studies that have found no association between age-related maculopathy and fibrinogen ${ }^{19,27,29,50}$ and $\mathrm{VWF}^{29,50}$ but others reported a positive association between fibrinogen and $\mathrm{AMD}^{14}$ and exudative macular degeneration ${ }^{51}$ after adjustment for key confounders. Case-control studies have reported higher levels of fibrinogen ${ }^{26,52}$ and VWF levels in AMD cases, ${ }^{26,53}$ but these analyses were not adjusted for potential confounding from age, sex, and smoking. The body evidence suggests that any associations of fibrinogen and VWF with AMD are likely to be weak and confounding by age, sex, and particularly smoking status needs to be taken into account. There does not appear to be any evidence to suggest that FVIIIc or t-PA activity is related to AMD.

One potential disadvantage of this study is the use of hospital controls that may have resulted in selection bias. However, funding and feasibility of the study negated the use of randomly selected controls (by age and sex) from the community. Controls in this study were attending the hospital for a variety of other ocular complaints and did not show any signs of age-related maculopathy. In agreement with another hospital-based case-control study, we were unable to confirm the association between smoking and AMD. ${ }^{54}$ The hospital in this study serves a local community in East London that is relatively socially deprived and may have resulted in more closely matched cases and controls with respect to confounders associated with geographical location such as smoking status. However, this allowed the influence of other risk factors to be assessed over and above any confounding by, for example smoking. Another potential limitation of this study is the pooling of two forms of AMD that may have a different epidemiological aetiology, but this is difficult to reconcile when examining systemic risk factors and because both types of AMD can exist in the same patient. Although the sample size in this study was relatively small, associations with established cardiovascular risk factors agreed with the published literature and provide some evidence of study validity. In agreement with other larger studies of early or late age-related maculopathy, after adjustment for age, sex, and smoking, we found overweight or obese individuals to have double the risk of $\mathrm{AMD} ;^{7,14,17}$ a weak inverse association with total serum cholesterol and AMD (OR $=0.77$ per $1 \mathrm{mmol} / 1$ increase in cholesterol; 95\% CI $0.57-1.05){ }^{14,19,24,51,55}$ no association with blood pressure; ${ }^{16,19,20,51,55}$ diagnosis or treatment for hypertension in crude $\mathrm{e}^{20,56}$ or adjusted analyses ${ }^{14,16,19,49,51,55,56}$ nor with a range or cardiovascular medications. ${ }^{49}$

The response rate was reasonable for a study in the elderly population. Misclassification of cases and controls was addressed by having a standardised protocol to separate study groups clearly. This resulted in a small number of individuals having to be excluded because they could not be classified as a definite case or definitive control. Also imbalances in age and sex were taken into account in all analyses. Observer bias was minimised because the nurse recruiting the patients was trained to collect the data from patients using a standardised procedure and the clinician categorising the patients into cases and controls from fundus photographs was blinded to data collected on other potential risk factors recorded on the questionnaire and biochemical measurements. The repeated measures of the analytes (which is rarely undertaken) allowed more precise estimates of the associations to be made than with single measures that tend to underestimate effects because of regression to the mean.

The association of AMD with FVII (and possibly with F1.2 and aspirin) may be a chance finding. The lack of an association with other thrombotic markers could be due to selective survival, in that individuals with less favourable atherothrombotic risk factor profiles died younger and so are not included in the study, leading to potentially biased estimates. It is possible that the study was not powered sufficiently to detect small but important associations between AMD and systemic makers of thrombosis or AMD may be related to local rather than systemic thrombotic activity.

In summary, this hospital-based case-control study found an inverse association between AMD and FVIIc and weaker evidence for F1.2. The results from this study do not provide strong evidence of systemic markers of arterial thrombosis as a mechanism in AMD, but the potential effects of FVIIc and F1.2, possibly through angiogenic pathways, are worthy of further investigation. 


\section{Summary}

\section{What was known before}

- Previous studies have shown associations between AMD and established cardiovascular disease risk factors, such smoking status, obesity, and markers of atherosclerotic disease. Studies reported associations between markers of systemic inflammation, including fibrinogen, tissue plasminogen activator, and von Willebrand factor. These same factors are related thrombogenesis in cardiovascular disease, but there is limited evidence examining the association between AMD and systemic markers of arterial thrombosis.

\section{What this study adds}

- We examined six markers of systemic atherothrombosis, including fibrinogen, factor VII, factor VIII, prothrombin fragment F1.2, tissue plasminogen activator antigen activity, and von Willebrand factor. Results suggest that the coagulation marker factor VIIc in particular, and to a lesser extent prothrombin fragment F1.2 (a molecular marker of thrombin generation in vivo) are inversely related to the risk of AMD.

\section{Conflict of interest}

The authors declare no conflict of interest.

\section{Acknowledgements}

We thank Liz McCabe for recruitment of the participants in the study, Jackie Cooper for monitoring matching during recruitment, and Homeira Sheikh for performing all the laboratory analyses. We also thank Mr Ivor Levy (deceased) for his contribution in interpretation of the retinal photographs and Bob Tapper for performing the photographs. This research was funded by the Medical Research Council.

Author contributions: All authors contributed to the formulation of the hypothesis. PM, RW, and TWM were responsible for the design and conduct of the study. ARR performed the statistical analyses and drafted the paper, to which all authors contributed. PM and TWM supervised the laboratory analyses. All authors approved the final version. PM and ARR had full access to all the data in the study and take responsibility for the integrity of the data and the accuracy of the data analysis.

\section{References}

1 Bunce C, Evans J, Fraser S, Wormald R. BD8 certification of visually impaired people. Br J Ophthalmol 1998; 82: 72-76.

2 Evans JR, Fletcher AE, Wormald RP. Age-related macular degeneration causing visual impairment in people 75 years or older in Britain: an add-on study to the Medical Research Council Trial of Assessment and Management of Older People in the Community. Ophthalmology 2004; 111: 513-517.
3 Congdon N, O'Colmain B, Klaver CC, Klein R, Muñoz B, Friedman DS et al. Causes and prevalence of visual impairment among adults in the United States. Arch Ophthalmol 2004; 122: 477-485.

4 Owen CG, Fletcher AE, Donoghue M, Rudnicka AR. How big is the burden of visual loss caused by age related macular degeneration in the United Kingdom? $\mathrm{Br} \mathrm{J}$ Ophthalmol 2003; 87: 312-317.

5 Friedman DS, O'Colmain BJ, Munoz B, Tomany SC, McCarty C, de Jong PT et al. Prevalence of age-related macular degeneration in the United States. Arch Ophthalmol 2004; 122: 564-572.

6 de Jong PT. Age-related macular degeneration. $N$ Engl J Med 2006; 355: 1474-1485.

7 Smith W, Assink J, Klein R, Mitchell P, Klaver CC, Klein BE et al. Risk factors for age-related macular degeneration: pooled findings from three continents. Ophthalmology 2001; 108: 697-704.

8 Evans JR, Fletcher AE, Wormald RP. 28000 Cases of age related macular degeneration causing visual loss in people aged 75 years and above in the United Kingdom may be attributable to smoking. Br J Ophthalmol 2005; 89: 550-553.

9 Thornton J, Edwards R, Mitchell P, Harrison RA, Buchan I, Kelly SP et al. Smoking and age-related macular degeneration: a review of association. Eye 2005; 19: 935-944.

10 Klein R, Deng Y, Klein BE, Hyman L, Seddon J, Frank RN et al. Cardiovascular disease, its risk factors and treatment, and age-related macular degeneration: Women's Health Initiative Sight Exam ancillary study. Am J Ophthalmol 2007; 143: 473-483.

11 Sperduto RD, Hiller R. Systemic hypertension and age-related maculopathy in the Framingham Study. Arch Ophthalmol 1986; 104: 216-219.

12 Chaine G, Hullo A, Sahel J, Soubrane G, Espinasse-Berrod MA, Schutz D et al. Case-control study of the risk factors for age related macular degeneration. France-DMLA Study Group. Br J Ophthalmol 1998; 82: 996-1002.

13 Mares-Perlman JA, Brady WE, Klein R, VandenLangenberg GM, Klein BE, Palta M. Dietary fat and age-related maculopathy. Arch Ophthalmol 1995; 113: 743-748.

14 Smith W, Mitchell P, Leeder SR, Wang JJ. Plasma fibrinogen levels, other cardiovascular risk factors, and age-related maculopathy: the Blue Mountains Eye Study. Arch Ophthalmol 1998; 116: 583-587.

15 Hyman L, Schachat AP, He Q, Leske MC. Hypertension, cardiovascular disease, and age-related macular degeneration. Age-Related Macular Degeneration Risk Factors Study Group. Arch Ophthalmol 2000; 118: 351-358.

16 Delcourt C, Michel F, Colvez A, Lacroux A, Delage M, Vernet $\mathrm{MH}$ et al. Associations of cardiovascular disease and its risk factors with age-related macular degeneration: the POLA study. Ophthalmic Epidemiol 2001; 8: 237-249.

17 Schaumberg DA, Christen WG, Hankinson SE, Glynn RJ. Body mass index and the incidence of visually significant age-related maculopathy in men. Arch Ophthalmol 2001; 119: 1259-1265.

18 Klein R, Klein BE, Tomany SC, Moss SE. Ten-year incidence of age-related maculopathy and smoking and drinking: the Beaver Dam Eye Study. Am J Epidemiol 2002; 156: 589-598.

19 Klein R, Klein BE, Marino EK, Kuller LH, Furberg C, Burke GL et al. Early age-related maculopathy in the cardiovascular health study. Ophthalmology 2003; 110: 25-33.

20 Vingerling JR, Dielemans I, Bots ML, Hofman A, Grobbee $\mathrm{DE}$, de Jong PT. Age-related macular degeneration is 
associated with atherosclerosis. The Rotterdam Study. Am J Epidemiol 1995; 142: 404-409.

21 Sato E, Feke GT, Appelbaum EY, Menke MN, Trempe CL, McMeel JW. Association between systemic arterial stiffness and age-related macular degeneration. Graefes Arch Clin Exp Ophthalmol 2006; 244: 963-971.

22 Wong TY, Tikellis G, Sun C, Klein R, Couper DJ, Sharrett AR. Age-related macular degeneration and risk of coronary heart disease: the Atherosclerosis Risk in Communities Study. Ophthalmology 2007; 114: 86-91.

23 Duan Y, Mo J, Klein R, Scott IU, Lin HM, Caulfield J et al. Age-related macular degeneration is associated with incident myocardial infarction among elderly Americans. Ophthalmology 2007; 114: 732-737.

24 Klein R, Clegg L, Cooper LS, Hubbard LD, Klein BE, King $\mathrm{WN}$ et al. Prevalence of age-related maculopathy in the Atherosclerosis Risk in Communities Study. Arch Ophthalmol 1999; 117: 1203-1210.

25 Cheung N, Liao D, Islam FM, Klein R, Wang JJ, Wong TY. Is early age-related macular degeneration related to carotid artery stiffness? The Atherosclerosis Risk in Communities Study. Br J Ophthalmol 2007; 91: 430-433.

26 Lip PL, Blann AD, Hope-Ross M, Gibson JM, Lip GY. Agerelated macular degeneration is associated with increased vascular endothelial growth factor, hemorheology and endothelial dysfunction. Ophthalmology 2001; 108: 705-710.

27 Dasch B, Fuhs A, Behrens T, Meister A, Wellmann J, Fobker $\mathrm{M}$ et al. Inflammatory markers in age-related maculopathy: cross-sectional analysis from the Muenster Aging and Retina Study. Arch Ophthalmol 2005; 123: 1501-1506.

28 Schaumberg DA, Christen WG, Buring JE, Glynn RJ, Rifai N, Ridker PM. High-sensitivity C-reactive protein, other markers of inflammation, and the incidence of macular degeneration in women. Arch Ophthalmol 2007; 125: 300-305.

29 Wu KH, Tan AG, Rochtchina E, Favaloro EJ, Williams A, Mitchell $\mathrm{P}$ et al. Circulating inflammatory markers and hemostatic factors in age-related maculopathy: a population-based case-control study. Invest Ophthalmol Vis Sci 2007; 48: 1983-1988.

30 Seddon JM, Gensler G, Milton RC, Klein ML, Rifai N. Association between $\mathrm{C}$-reactive protein and age-related macular degeneration. JAMA 2004; 291: 704-710.

31 Klein R, Klein BE, Knudtson MD, Wong TY, Shankar A, Tsai MY. Systemic markers of inflammation, endothelial dysfunction, and age-related maculopathy. Am J Ophthalmol 2005; 140: 35-44.

32 Seddon JM, Gensler G, Klein ML, Milton RC. C-reactive protein and homocysteine are associated with dietary and behavioral risk factors for age-related macular degeneration. Nutrition 2006; 22: 441-443.

33 Shankar A, Mitchell P, Rochtchina E, Tan J, Wang JJ. Association between circulating white blood cell count and long-term incidence of age-related macular degeneration: the Blue Mountains Eye Study. Am J Epidemiol 2007; 165: 375-382.

34 Meade TW, North WR, Chakrabarti R, Stirling Y, Haines AP, Thompson SG et al. Haemostatic function and cardiovascular death: early results of a prospective study. Lancet 1980; 1: 1050-1054.

35 Cooper JA, Miller GJ, Bauer KA, Morrissey JH, Meade TW, Howarth DJ et al. Comparison of novel hemostatic factors and conventional risk factors for prediction of coronary heart disease. Circulation 2000; 102: 2816-2822.
36 Rudnicka AR, Mt-Isa S, Meade TW. Associations of plasma fibrinogen and factor VII clotting activity with coronary heart disease and stroke: prospective cohort study from the screening phase of the Thrombosis Prevention Trial. J Thromb Haemost 2006; 4: 2405-2410.

37 De Stavola BL, Meade TW. Long-term effects of hemostatic variables on fatal coronary heart disease: 30 -year results from the first prospective Northwick Park Heart Study (NPHS-I). J Thromb Haemost 2007; 5: 461-471.

38 Fibrinogen Studies Collaboration. Plasma fibrinogen level and the risk of major cardiovascular diseases and nonvascular mortality: an individual participant metaanalysis. JAMA 2005; 294: 1799-1809.

39 Whincup PH, Danesh J, Walker M, Lennon L, Thomson A, Appleby $\mathrm{P}$ et al. von Willebrand factor and coronary heart disease: prospective study and meta-analysis. Eur Heart $J$ 2002; 23: 1764-1770.

40 Lowe GD, Danesh J, Lewington S, Walker M, Lennon L, Thomson A et al. Tissue plasminogen activator antigen and coronary heart disease. Prospective study and metaanalysis. Eur Heart J 2004; 25: 252-259.

41 Bird AC, Bressler NM, Bressler SB, Chisholm IH, Coscas G, Davis MD et al. An international classification and grading system for age-related maculopathy and age-related macular degeneration. The International ARM Epidemiological Study Group. Surv Ophthalmol 1995; 39: 367-374.

42 von Clauss A. Rapid physiological coagulation method in determination of fibrinogen. Acta Haematol 1957; 17: 237-246.

43 Miller GJ, Stirling Y, Esnouf MP, Heinrich J, van de Loo J, Kienast J et al. Factor VII-deficient substrate plasmas depleted of protein $\mathrm{C}$ raise the sensitivity of the factor VII bio-assay to activated factor VII: an international study. Thromb Haemost 1994; 71: 38-48.

44 Armstrong BG. The effects of measurement errors on relative risk regressions. Am J Epidemiol 1990; 132: 1176-1184.

45 MacCallum PK, Cooper JA, Martin J, Howarth DJ, Meade TW, Miller GJ. Haemostatic and lipid determinants of prothrombin fragment F1.2 and D-dimer in plasma. Thromb Haemost 2000; 83: 421-426.

46 Anderssen T, Halvorsen H, Bajaj SP, Osterud B. Human leukocyte elastase and cathepsin G inactivate factor VII by limited proteolysis. Thromb Haemost 1993; 70: 414-417.

47 Klein R, Klein BE, Tomany SC, Cruickshanks KJ. Association of emphysema, gout, and inflammatory markers with long-term incidence of age-related maculopathy. Arch Ophthalmol 2003; 121: 674-678.

48 Christen WG, Glynn RJ, Ajani UA, Schaumberg DA, Chew EY, Buring JE et al. Age-related maculopathy in a randomized trial of low-dose aspirin among US physicians. Arch Ophthalmol 2001; 119: 1143-1149.

49 Klein R, Klein BEK, Jensen SC, Cruickshanks KJ, Lee KE, Danforth LG et al. Medication use and the 5-year incidence of early age-related maculopathy - the Beaver Dam eye study. Arch Ophthalmol 2001; 119: 1354-1359.

50 Wang JJ, Ross RJ, Tuo J, Burlutsky G, Tan AG, Chan CC et al. The LOC387715 polymorphism, inflammatory markers, smoking, and age-related macular degeneration. A population-based case-control study. Ophthalmology 2008; 115: 693-699.

51 Klein R, Klein BE, Jensen SC, Mares-Perlman JA, Cruickshanks KJ, Palta M. Age-related maculopathy in a 
multiracial United States population: the National Health and Nutrition Examination Survey III. Ophthalmology 1999; 106: 1056-1065.

52 The eye disease case-control study group. Risk factors for neovascular age-related macular degeneration. The eye disease case-control study group. Arch Ophthalmol 1992; 110: 1701-1708.

53 Malukiewicz-Wisniewska G, Rosc D, Kaluzny B, Kaluzny JJ. von Willebrand factor in plasma of patients with age related macular degeneration. (Polish). Klinika Oczna 2005; 107: $70-72$.
54 Tao Y, Jonas JB. Refractive error and smoking habits in exudative age-related macular degeneration in a hospital-based setting. Eye 2009. e-pub ahead of print; doi: 10.1038/eye.2009.160.

55 Klein R, Klein BE, Tomany SC, Cruickshanks KJ. The association of cardiovascular disease with the long-term incidence of age-related maculopathy: the Beaver Dam Eye Study. Ophthalmology 2003; 110: 1273-1280.

56 Hirvela H, Luukinen H, Laara E, Sc L, Laatikainen L. Risk factors of age-related maculopathy in a population 70 years of age or older. Ophthalmology 1996; 103: 871-877. 